\title{
REKONSTRUKSI GERAK PADA TARI REMO TAWI JOMBANG
}

\author{
Oleh: Ayu Titis Rukmana Sari, M.Sn* dan Wahyudi, M.Sn.** \\ Dosen Universitas Nusantara PGRI Kediri \\ Email: ayutitis@unpkediri.ac.id
}

\begin{abstract}
RINGKASAN
Tari Remo Tawi merupakan salah satu Tari Remo di Jawa Timur yang memiliki ciri khas tersendiri dibandingkan dengan Tari Ngremo lainnya.Tari ini diciptakan oleh Tawi seorang pengreman dari Jombang. Tawi mengolah gerakan, sehingga mampu memunculkan teknik gerak yang unik dan berbeda dengan Tari Remo lainnya, yakni lebih halus (kêmayu), mencerminkan karakter dari Tawi yang merupakan sosok pria feminin dan berkarakter luruh atau halus

Tujuan penelitian ini adalah menghasilkan warna baru dalam sajian Tari Remo Tawi. Warna baru yang dimaksud disesuaikan dengan kebutuhan masyarakat saat ini, yang cenderung mengutamakan kebutuhan visual dan berdurasi singkat. Unsur visual yang utama dalam sebuah sajian tari adalah gerak, maka gerak dalam Tari Remo Tawi dilakukan proses rekonstruksi oleh peneliti untuk mempertahankan eksistensinya di tengah masyarakat modern. Metode yang digunakan dalam penelitian ini adalah metode deskriptif analisis kualitatif dengan pendekatan etnokoreologi.

Hasil penelitian ini dapat digunakan sebagai pedoman bagi para seniman tari khususnya tentang cara-cara merekontruksi tari agar lebih memiliki kesan yang menarik masyarakat pada umumnya, namun tetap mempertahankan esensi/nilai dan mengindari distorsi yang berlebihan sehingga eksistensi dari tari tersebut tetap bertahan ditengah derasnya arus globalisasi.
\end{abstract}

Kata kunci :Rekonstruksi Gerak, Tari Remo Tawi

\section{ABSTRACT}

Tawi Dance is one of Remo Dance in East Java which has its own distinctive character compared with other Ngremo Dance. This dance was created by Tawi a pengreman from Jombang.Tawi cultivate the movement in such a way, so as to bring up a unique motion technique and different from Remo Dance which others. The gentle rustle (kêmayu), reflects the individual 
character of Tawi which is the figure of the feminine man and the character is decayed or subtle.

The purpose of this research is to produce new color in Remo Tawi Dance dish. The new colors are adapted to the needs of today's society, which tend to prioritize visual needs and short duration. The main visual element in a dish of dance is motion, then the motion in Remo Tawi Dance done reconstruction process by researchers to maintain its existence in the middle of modern society. The method used in this research is descriptive method of qualitative analysis by using ethnokoreologi approach.

The results of this study can be used as a guideline for dance artists, especially on ways to reconstruct dance to have a more interesting impression of society in general, but still maintain the essence / value and avoid excessive distortion so that the existence of the dance survives amid the swift stream of globalization.

Keywords: Motion Reconstruction, Remo Tawi Dance

\section{PENDAHULUAN}

Tari hadir karena penari, artinya bahwa keberadaan penari menjadi penting sebagai media untuk mengaktualisasikan tari, maka keberadaannya tidak hanya dikatakan sebagai tukang tari tetapi sebagai seniman. Seniman adalah istilah subjektif yang merujuk kepada seseorang yang kreatif, inovatif, atau mahir dalam bidang seni. Seniman menggunakan imajinasi dan bakatnya untuk menciptakan karya dengan nilai estetika. Ahli sejarah seni dan kritikus seni mendefinisikan seniman sebagai seseorang yang menghasilkan karya seni.

Penciptaan sebuah karya Seni Tari pada hakikatnya merupakan kreativitas dari seniman yang telah melalui proses penghayatan seluruh pengalaman jiwa. Melalui penjelajahan terhadap berbagai pengalaman kejiwaan dalam aktivitas penghayatan, menuju pemaknaan yang tervisualisasikan dalam konstruksi gerakangerakan tubuhnya. Dalam proses yang mendalam inilah kemudian melahirkan 2 sebutan seniman yakni seniman pencipta dan seniman 'interpreter'.(Wahyudianto, 2008:87)

Seniman pencipta yaitu yang membuat sebuah karya-karya baru baik itu tari, rupa, teater dan musik. Dalam seni tari pencipta disebut kreator, yang menghasilkan karya tari baru dari bentuk ide estetik yang kemudian diwujudkan kedalam wujud fisik sehingga terjadi proses komunikasi antara kreator, penari dan penonton. Dalam penampilan suatu 
karya seni, peran penari dan penonton juga memiliki andil yang penting.

Penari adalah pelaku atau subjek yang mengaktualisasikan kembali karya seniman pencipta dalam suatu karya seni tari dengan takaran interpretasi tertentu. Penari juga merupakan seniman, yakni seniman interpreter.Seniman yang mengaktualisasikan karya seniman pencipta tari.“" Penari sebagai sarana dalam ekspresi seni tari. Dijelaskan lebih lanjut seniman pencipta tari adalah pemegang ide terbesar tetapi penari adalah motornya". (Yulianti Parani, 1986:54 dalam Wahyudiyanto 2008: 90)

Asumsi yang memperkuat pemahaman bahwa penari adalah seniman dan bukan sekedar robot yakni bahwa tari meliputi 2 dimensi yang tertuang secara visual dan sisi lain bersifat presentasional yang tersingkap melaui rasa (penghayatan). Istilah yang disebut terakhir ini kemudian menjelma menjadi sesuatu yang sering dikatakan sebagai "Ruh" dari sebuah tarian (Chaya, 2003:291 dalam Wahyudiyanto 2008:91). Tari yang terbentuk sebagai koreografi adalah aspek wadah atau wujud fisik dalam bentuk inderawi, dan isi yang hadir melalui proses hayatan terhadap wujud ungkapnya. Seorang penari menyajikan isi pada konsep koreografinya, bagaimana supaya tari tersebut hidup pada dirinya dalam rangka mencapai estetika (boleh, perlu, bahkan wajib).
Dalam menyajikan sebuah repertoar tari, penari dituntut mampu melakukan interpretasi atau menafsirkan, baik isi atau karakter tari yang disajikan maupun terhadap keseluruhan pelaksanaan teknik secara utuh.Selama pertunjukan, penari (secara konsisten) melakukan interpretasi sebuah tarian (Adshead, 1988:62 dalam Wahyudiyanto, 2008:94). Niscaya tanpa penafsiran dan penghayatan seorang penari tidak akan mampu menghadirkan daya ungkap yang kuat menjelma dalam pancaran 'Ruh' dari sajian suatu tari. Dalam konteks itu penari dapat dikategorikan sebagai seniman interpretatif atau seniman penafsir (Sri Rochana W., 1997:88 dalam Wahyudianto, 2008:94).

Seniman interpreter yaitu seniman kreatif yang menyangkut pemikiran imajinatif.Kemampuan kreativitas adalah kemampuan untuk mencipta, memberi interpretasi, mewujudkan ide, gagasan dan pengalaman ke dalam sebuah bentuk seni yang disertai daya imajinasi dan inovasi yang tinggi.

Di dalam proses rekonstruksi gerak dibutuhkan kreativitas. Rekonstruksi gerak yaitu : proses mengembangkan dan merubah gerak dari gerak yang sudah ada ke bentuk gerak yang baru. Proses inilah yang membutuhkan kreativitas dari peneliti yang berperan juga sebagai penari. Mengubah serta mengembangkan bentuk dari yang sudah ada 
ke bentuk baru, namun juga mempertimbangkan esensi dari tari itu sendiri. Maka dalam proses ini peneliti sebagai penari dalam melakukan proses rekonstruksi atau menafsir kembali dapat disebut sebagai seniman interpreter.

Peran seorang penari sangat penting dalam sebuah jenis tarian saat menarikannya. Paling tidak terdapat beberapa hal yang dapat disebut sebagai bekal yang harus dikuasai oleh penari, yakni :

a. Intuisi dan imajinasi, adalah pergerakan naluri seorang penari untuk memotivasi serta penafsiran pengalaman imajinatif ke dalam pengalaman fisiknya.

b. Pengetahuan materi gerak, adalah gerak sebagai medium pokok, harus dipahami dari berbagai aspek, yaitu dari segi bentuk, kualitas, teknik, struktur komposisi, sampai dengan gaya, karakter dan isi.

c. Pengetahuan bentuk bidang estetika, dapat dipahami bahwa seorang penari harus memiliki wawasan serta nilai estetika sebagai salah satu bagian dari penelitian tari.

d. Pengetahuan dramatik, adalah kemampuan akting atau kemampuan membawakan peran tertentu

e. Kesiapan fisik, dapat dimaknai sebagai suatu hal yang sangat diperlukan dalam mencapai fungsi tubuh sebagai sumber gerak.

Peneliti yang sekaligus berperan sebagai penari melakukan proses kreatif tidak saja dari segi bentuk fisik penelitiannya, namun juga proses kreatif yang dituangkan melalui penafsiran. Tafsir adalah suatu proses kerja yang diungkapan melalui ide imajiner serta kemudian diaktualisasikan ke dalam wujud dengan menggunakan tubuh sebagai wadah sehingga diharapkan muncul warna baru tanpa meninggalkan nilai-nilai, aturan atau kaidah yang sudah ada. Artinya menyajikan tari bukan hanya sekedar menampilkan bentuk secara alami apa adanya, namun dalam penjabarannya diperlukan pemahaman dan pendalaman filosofi atau nilai yang terkandung di dalam tari itu sendiri, sehingga secara analisis baik gerak ataupun karakter tari yang disajikan dapat memiliki kesan hidup.

S.D.Humardani mengetengahkan sebuah pemikiran tentang kreativitas:

Kemampuan untuk menghasilkan sesuatu yang baru, yaitu yang sebelumnya belum dihasilkan. Dapat orang melihat lebih lanjut sedikit dalam proses kegiatan yang baru ini : Kreativitas adalah kemampuan menghubungkan hal-hal yang sebelumnya belum dihubungkan. (Humardani, 1980:66)

Pendapat tersebut menunjukkan bahwa tafsir muncul ketika ada proses, dan proses kreatif penari terjadi ketika aktivitas kesenian 


\section{JOGED}

ISSN: $1858-3989$

berlangsung. Kreatif dalam konteks tradisi berarti menemukan warna baru dalam sajian yang sudah ada dengan mengkaitkan ide-ide imajiner ke dalam bentuk yang terdahulu untuk dijadikan kekinian, menjadi tampilan yang baru dari unsur-unsur seninya. Menurut Wahyudianto:

"Kreatif sebagai kecerdasan pada tataran ini melampaui kecerdasan intelektual dan dari sekedar tampil. Kreatif sebagai proses kerja pada bingkai ini selain memerlukan kesiapan material fisik dan non fisik yang harus terkuasai terlebih dahulu dengan baik dan matang kreatif juga belum dengan mudah dapat diberdayakan kecuali dengan ketekunan, keuletan dalam proses kerja teknik, intelektual, dan intuitif dalam tekanan rasa jiwa yang besar". (Wahyudianto, 2007:44)

Dilihat dari bentuk dan gaya Tari Remo yang terdapat di Jawa Timur, salah satu Tari Remo Jombangan karya Tawi memiliki keunikan tersendiri dalam teknik geraknya. Pada kebanyakan Tari Remo putri karakter geraknya cenderung masih dinamis, seperti Tari Remo Trisnawati dengan karakter dinamis, volume gerak yang lebar dan kelincahannya, Tari Remo Tubi dengan karakter dinamis, volume gerak yang lebar, namun lebih tenang pergerakannya tidak banyak berpindah tempat. Tari Remo Tawi ini memiliki karakter gerak yang lebih luwes, lembut, kenes, volume gerak yang kecil sesuai dengan karakter penciptanya seorang pria
Ayu Titis Rukmana Sari, M.Sn* dan Wahyudi, M.Sn.** (REKONSTRUKSI GERAK PADA TARI REMO TAWI JOMBANG)

namun memiliki karakter yang lembut dan luwes.

Penciptaan Tari Remo Tawi tidak lepas dari peran serta sosok Tawi sebagai koreografer atau penciptanya. Tawi merupakan salah satu seniman tradisi yang berkecimpung di dunia seni sejak berusia 35 tahun dan bertempat tinggal di Jl. Raya Ploso Kecamatan Tembelang Kabupaten Jombang.

Tawi menciptakan Tari Remo selain lahir secara alamiah, juga mendapat inspirasi dari penari-penari Remo sebelumnya. Tari Remo yang ditarikan Tawi merupakan satu rangkaian dengan pertunjukan Ludruk dan digunakan sebagai tarian pembuka.

Pada perkembangan saat ini Tari Remo Tawi sudah jarang dipentaskan kembali, dikarenakan sosok Tawi sendiri yang sudah tua dan mendapat larangan dari keluarga. Selain itu, salah satu alasan terkuat Tawi yaitu: Tari Remo saat ini sudah kehilangan konsep seniti (seni hati), beliau lebih menyebut hal ini sebagai distorsi atau pemaksaan bentuk gerak (fisik lebih diutamakan dalam mencapai teknik daripada råså), sehingga kondisi Tari Remo saat ini terkesan kaku atau mêkêkêngkêng tidak lagi ora ndayani. Pemahaman seperti tentang konsep seniti tersebut menjadi berbanding terbalik dengan perkembangan Tari Remo pada saat ini yang lebih mengutamakan pada kesempurnaan bentuk fisik, sehingga agak jauh dari kesempurnaan dan penyatuan sebuah 
penyajian tari yang terkonsep dari segi bentuk dan isi.

Oleh karena itu, peneliti tertarik untuk merekonstruksi kembali Tari Remo Tawi agar lebih diminati masyarakat dan tari ini tidak tenggelam begitu saja. Berdasarkan fenomena tersebut, penelitian tentang Remo Tawi penting untuk dilakukan, sehingga judul penelitian ini adalah "Rekonstruksi Gerak Pada Tari Remo Tawi Jombang”.

Berdasarkan latar belakang tersebut, menjadi penting untuk merekonstruksi kembali gerak dari Tari Remo Tawi untuk memberikan warna baru pada sajiannya. Dari pembaharuan warna tersebut diharapkan mampu melahirkan karya Tari Ngremo Jombangan yang unik, menarik dan diminati masyarakat. Hal ini yang menjadikan Tari Remo Jombangan dapat terus berkembang sampai sekarang. Berdasarkan fenomena tersebut, penelitian tentang Rekonstruksi Gerak Pada Tari Remo Tawi penting untuk dilakukan, sehingga rumusan masalah yang diangkat adalah Bagaimana cara merekonstruksi gerak Tari Remo Tawi Jombang dengan kebaharuan dalam segi tafsir gerak?"

Tujuan penelitian ini adalah untuk Memberikan warna baru pada sajian Tari Remo Tawi dalam segi tafsir gerak. Manfaat dari penelitian ini dapat memberikan sumbangan keilmuan tentang keanekaragaman gaya atau style Tari Remo yang ada di Jawa
Timur khususnya di Jombang.

\section{PEMBAHASAN}

Proses pertumbuhan dan perubahan sosial membuat kesenian juga ikut berkembang sesuai dengan apa yang dikehendaki dan dicita-citakan masyarakat yang bersangkutan. Serta mengingat pula bahwa kesenian selalu mengikuti gerak perubahan kebudayaan.

Jawa Timur menurut catatan sejarah pernah mempunyai kerajaan, seperti Singasari, Kediri dan Majapahit merupakan suara daerah yang kaya dengan jenis kebudayaan. Mengingat bahwa suatu kerajaan merupakan suatu pusat kehidupan budaya tertentu menurut kondisi pada masa itu. Sehingga dengan demikian kondisi budaya pada jaman kerajaan Kediri berbeda dengan kondisi budaya pada jaman kerajaan Majapahit.

Berbicara masalah budaya, maka tidak lepas dari masalah kesenian. Mengingat bahwa kesenian merupakan salah satu unsur dari kebudayaan, salah satu contoh adalah kesenian Ludruk yang pada saat ini berkembang cukup meluas merupakan kesenian yang digemari banyak masyarakat Jawa Timur. Begitu pula Tari Remo sebagai tari pembuka dalam kesenian Ludruk mempunyai masyarakat pendukung yang berbeda, sesuai dengan selera maupun nilai yang berkembang pada kehidupan budayanya. 
Oleh karena itu kegiatan Tari Remo akan jauh lebih banyak daripada Ludruk yang ada. Maka tidak mustahil kalau sampai terjadi banyak jenis Tari Remo yang mempunyai rasa kedaerahan maupun rasa ungkap dari masingmasng seniman. Namun demikian, mengingat tari tradisi menggunakan vokabuler yang ada dan bertumpu atau berpedoman pada masa lampau maka sudah barang tentu bentuk Tari Remo yang ada di Jawa Timur mempunyai banyak kemiripan antara daerah yang satu dengan daerah yang lain. Sehingga menjadikan ciri khas tersendiri bagi seniman pencipta atau daerah yang menjadi tempat tinggal seniman pencipta.

Dalam proses tafsir gerak Tari Remo Tawi peneliti sekaligus pelaku melakukan banyak tafsir gerak dari yang telah ada menjadi bentuk baru yang lebih jelas dari pola gerak, hitungan, volume gerak dan juga pemotongan penyajian dari durasi yang semula berkisar \pm 30 menit dipadatkan menjadi 12 menit. Sehingga memudahkan untuk siapapun yang ingin mempelajari Tari Remo Tawi. Ditilik dari ukuran pembelajaran materi tersebut kurang memenuhi kriteria, utamanya dari tuntutan kerumitan dan kajian estetiknya sehingga dibutuhkan totalitas penafsiran pada garap mediumnya. Ukuran pembelajaran tersebut diperlukan sebagai pertimbangan untuk keberlanjutan yang berkualitas sehingga memungkinkan kesenian atau suatu repertoar tari mampu mempertahankan eksistensinya ditengah derasnya arus budaya global. Tuntutan tersebut peneliti terjemahkan dengan menafsirkan kembali materi tari tersebut, misalnya pada salah satu bagian gerak adêg. Bentuk adêg tersebut dari sudut pandang untuk pembelajaran yang dibawakan oleh narasumber kurang menarik sehingga diperlukan tafsir yakni memberi tenaga pada kaki. Posisi tersebut akan membuat adêg menjadi lebih mêndhak serta posisi tangan, bentuk dan gerakannya lebih diperjelas. Dari proses penafsiran tersebut diharapkan dapat mengungkapkan kebaruan yang mempribadi atau style personal peneliti.

Pada penjelasan deskripsi dibawah ini berisi rincian nama ragam, uraian penjelasan tentang ragam gerak yang dilakukan, hitungan pengulangan pada masing-masing ragam gerak. Kiranya perlu disampaikan bahwa penjelasan pada masing-masing bagian merupakan penjelasan secara umum mengingat detail dari masing-masing bagian merupakan satu kesatuan antara bentuk, teknik dan råså. Penjelasan tentang hal yang bersifat fisik dimungkinkan bisa dilakukan namun pada bagian råså sudah barang tentu tidak bisa diterjemahkan dan diukur dalam wujud kalimat tulis, mengingat ukuran råså dari masing-masing individu berbeda. 
Deskripsi secara umum dari Remo Putri gaya Tawi setelah proses rekonstruksi gerak dijelaskan sebagai berikut:

\begin{tabular}{|l|l|l|c|}
\hline No. & $\begin{array}{c}\text { Nama } \\
\text { Ragam }\end{array}$ & \multicolumn{1}{|c|}{ Uraian } & Hitungan \\
\hline 1. & Tindak & $\begin{array}{l}\text { Jalan biasa } \\
\text { kemudian } \\
\text { srisig menuju } \\
\text { ke center,posisi } \\
\text { adêg. }\end{array}$ & $2 \times 8$ \\
\hline 2. & $\begin{array}{l}\text { Gêdrug } \\
\text { låmbå }\end{array}$ & $\begin{array}{l}\text { Kêncrong } \\
\text { låmbå 6x, } \\
\text { gêjug hit 1 -2 } \\
\text { kemudian } \\
\text { kêncrong } \\
\text { låmbå lagi 4x, } \\
\text { hit. 5 -6 } \\
\text { seblak sampur } \\
\text { kanan. }\end{array}$ & $1-6$ \\
\hline
\end{tabular}

\begin{tabular}{|c|c|c|c|}
\hline 3 & $\begin{array}{l}\text { Gêdrug } \\
\text { rangkêp }\end{array}$ & $\begin{array}{l}\text { Kêncrong } \\
\text { rangkêp }\end{array}$ & $\begin{array}{c}7-8 \\
1 \times 8+4\end{array}$ \\
\hline 4. & Ikêt & $\begin{array}{l}\text { Mundur kaki } \\
\text { kiri, ukêl } \\
\text { tangan kanan, } \\
\text { kêbyok kêbyak } \\
\text { sampur kiri, } \\
\text { képat sampur } \\
\text { kanan. }\end{array}$ & $5-8$ \\
\hline 5. & Lawung & $\begin{array}{l}\text { Ukêl suwêng } \\
\text { kanan dan kiri } \\
\text { bergantian. }\end{array}$ & $1 \times 8+4$ \\
\hline 6. & $\begin{array}{l}\text { Gêdrug } \\
\text { rangkêp }\end{array}$ & $\begin{array}{l}\text { Kêncrong } \\
\text { rangkêp }\end{array}$ & $5-8+4$ \\
\hline 7. & Ikêt & $\begin{array}{l}\text { Mundur kaki } \\
\text { kiri, ukêl } \\
\text { tangan kanan, } \\
\text { kêbyok } \\
\text { kêbyaksampur } \\
\text { kiri, képat } \\
\text { sampur kanan }\end{array}$ & $5-8$ \\
\hline
\end{tabular}

\begin{tabular}{|l|l|l|c|}
\hline 8. & Sabêtan & $\begin{array}{l}\text { Junjungan kaki } \\
\text { kanan kêtêr, } \\
\text { kêbyok sampur } \\
\text { kiri, képat } \\
\text { sampur kanan, } \\
\text { gêjug kanan. }\end{array}$ & $1 \times 8$ \\
\hline 9. & Tindak & $\begin{array}{l}\text { Tindak låmbå } \\
\text { putar ke kanan }\end{array}$ & $1 \times 8+6$ \\
\hline 10. & $\begin{array}{l}\text { Gêdrug } \\
\text { rangkêp, }, \\
\text { ogèk }\end{array}$ & $\begin{array}{l}\text { Gêdrug } \\
\text { rangkêp, } \\
\text { sambil bahu } \\
\text { ogèk kanan kiri } \\
\text { dilakukan } \\
\text { rangkêp. }\end{array}$ & $2 \times 8+4$ \\
\hline
\end{tabular}

\begin{tabular}{|l|l|l|c|}
\hline 11. & Ikêt & $\begin{array}{l}\text { Mundur kaki } \\
\text { kiri, ukêl tangan } \\
\text { kanan, kêbyok } \\
\text { kêbyak sampur } \\
\text { kiri, sampur } \\
\text { kanan. }\end{array}$ & $5-8$ \\
\hline 12. & $\begin{array}{l}\text { Ayam } \\
\text { alas }\end{array}$ & $\begin{array}{l}\text { Jalan kecil-kecil } \\
\text { atau kêrêp }\end{array}$ & $1-4$ \\
\hline 13. & Ikêt & $\begin{array}{l}\text { Mundur kaki } \\
\text { kiri, ukêl tangan } \\
\text { kanan, kêbyok } \\
\text { kêbyak } \\
\text { sampur kiri, } \\
\text { sampur kanan. }\end{array}$ & $5-8$ \\
\hline 14. & Sabêtan & $\begin{array}{l}\text { Junjungan kaki } \\
\text { kanan kêtêr, } \\
\text { kêbyok sampur } \\
\text { kiri, sampur } \\
\text { kanan, gêjug } \\
\text { kanan. }\end{array}$ & $1 \times 8$ \\
15. & $\begin{array}{l}\text { Mundur kaki } \\
\text { kiri, ukêl tangan } \\
\text { kanan, kêbyok } \\
\text { kêbyaksampur } \\
\text { kiri,sampur } \\
\text { kanan. }\end{array}$ & $1-4$ \\
\hline
\end{tabular}




\begin{tabular}{|c|c|c|c|}
\hline 16. & $\begin{array}{l}\text { Kêbyok } \\
\text { képat } \\
\text { sampur }\end{array}$ & $\begin{array}{l}\text { Tangan kanan } \\
\text { kêbyok sampur } \\
\text { tangan kiri } \\
\text { seblak sampur } \\
\text { kaki kanan. }\end{array}$ & $5-8+8$ \\
\hline 17. & $\begin{array}{l}\text { Gêdrug } \\
\text { rangkêp }\end{array}$ & $\begin{array}{l}\text { Kencrongan } \\
\text { rangkêp, tangan } \\
\text { sambil ukêl-- } \\
\text { ukêl. }\end{array}$ & $1 \times 8+4$ \\
\hline 18. & Ikêt & $\begin{array}{l}\text { Mundur kaki } \\
\text { kiri ukêl tangan } \\
\text { kanan, kêbyok } \\
\text { kêbyaksampur } \\
\text { kiri, } \\
\text { képatsampur } \\
\text { kanan }\end{array}$ & $5-8$ \\
\hline 19. & $\begin{array}{l}\text { Nggêndé } \\
w a\end{array}$ & $\begin{array}{l}\text {-Képat sampur } \\
\text { kanan gêjug. } \\
\text {-Mundur gêjug- } \\
\text { gêjug. } \\
\text {-Maju kiri, } \\
\text { buang sampur, } \\
\text { ukêl kanan } \\
\text { kiri. } \\
\text {-nyawur sampur } \\
\text { kanan tangan } \\
\text { kiri ditarik ke } \\
\text { pinggang, } \\
\text { tangan kanan } \\
\text { ukêl sejajar } \\
\text { pinggang, } \\
\text { kepala toleh kiri. } \\
\text {-gêjugan lagi } \\
\text { ditempat }\end{array}$ & $1 \times 8+4$ \\
\hline 20. & Ikêt & $\begin{array}{l}\text { Mundur kaki } \\
\text { kiri, ukêl tangan } \\
\text { kanan, kêbyok } \\
\text { kêbyak sampur } \\
\text { kiri, képat } \\
\text { sampur kanan. }\end{array}$ & $5-8$ \\
\hline 21. & Lawung & $\begin{array}{l}\text {-Ukêl suwêng } \\
\text { kanan kiri 4x. } \\
\text {-Sêblak sampur, } \\
\text { kemudian ukêl } \\
\text { suwêng kiri 1x. } \\
\text {-Képat sampur, } \\
\text { gêdrug låmbå. }\end{array}$ & $1-8+4$ \\
\hline
\end{tabular}

\begin{tabular}{|c|c|c|c|}
\hline 22. & Ikêt & $\begin{array}{l}\text { Mundur kaki } \\
\text { kiri, ukêl } \\
\text { tangan kanan, } \\
\text { kêbyok kêbyak } \\
\text { sampur kiri, } \\
\text { képat sampur } \\
\text { kanan. }\end{array}$ & $5-8$ \\
\hline 23. & $\begin{array}{l}\text { Ukêl } \\
\text { suwêng }\end{array}$ & $\begin{array}{l}\text {-Ukêl suwêng } \\
\text { kanan dan kiri } \\
5 \text { 1⁄2 x. } \\
\text {-Penghubung } \\
1 \text { (képat } \\
\text { sampur } \\
\text { kanan, } \\
\text { kêncrong } \\
\text { rangkêp } \\
\text { sambil ogèk } \\
\text { bahu). } \\
\text {-Ukêl suwêng } \\
\text { 4x. } \\
\text {-Penghubung } \\
2 \text { (Ukêl kanan } \\
\text { kiri, } \\
\text { nyawuksampu } \\
\text { r kanan } \\
\text { tangan kiri } \\
\text { ditarik ke } \\
\text { pinggang, } \\
\text { toleh ke kiri, } \\
\text { képatsampur } \\
\text { kanan kiri, } \\
\text { kemudian } \\
\text { pous adêg). }\end{array}$ & $1-8+4$ \\
\hline 24. & $\begin{array}{l}\text { Ngrawit } \\
\text { ulap- } \\
\text { ulap }\end{array}$ & $\begin{array}{l}\text {-Ngrawit } \\
\text { kanan ulap- } \\
\text { ulap kanan, } \\
\text { ngrawit kiri } \\
\text { ulap-ulap kiri } \\
\text { 3x. } \\
\text {-Penghubung } \\
2 \text { (Penjelasan } \\
\text { idem). }\end{array}$ & $1-8+4$ \\
\hline
\end{tabular}




\begin{tabular}{|c|c|c|c|}
\hline 25. & $\begin{array}{l}\text { Kêncrongan } \\
\text { rangkêp }\end{array}$ & $\begin{array}{l}\text {-Kêncrongan } \\
\text { rangkêp ukêl- } \\
\text { ukêl, } \\
\text { kemudian hit } \\
8 \text { terakhir } \\
\text { képat sampur } \\
\text { kanan tangkap } \\
\text {-Diulang } \\
\text { kencrongan } \\
\text { lagi. } \\
\text {-Penghubung } 2 \\
\text { (idem). }\end{array}$ & $5-8+2 \times 8$ \\
\hline 26. & $\begin{array}{l}\text { Kêncrong } \\
\text { låmbå }\end{array}$ & $\begin{array}{l}\text { Gêjugan } \\
\text { låmbå }\end{array}$ & $\begin{array}{c}1 \times 8+4 \\
5-8+8 \\
+1-4\end{array}$ \\
\hline 27. & Ikêt & $\begin{array}{l}\text { Mundur } \\
\text { kiri, } \\
\text { tangi } \\
\text { takêl } \\
\text { kêbyok kêbyan, } \\
\text { sampur kiri, } \\
\text { képat sampur } \\
\text { kanan. }\end{array}$ & $5-8$ \\
\hline 28 . & $\begin{array}{l}\text { Tindak } \\
\text { double step } \\
\text { Dangdutan }\end{array}$ & $\begin{array}{l}\text {-Jalan double } \\
\text { step putar } \\
\text { kekanan. } \\
\text {-Mundur } \\
\text { kanan angkat } \\
\text { kaki kiri, } \\
\text { mundur kiri } \\
\text { angkat kaki } \\
\text { kanan 4x. } \\
\text {-Jalan geser } \\
\text { kesamping } \\
\text { arah 4 } \\
\text { penjuru, } \\
\text { junjungan } \\
\text { kaki kanan } \\
\text { dan kiri } \\
\text { bergantian, } \\
\text { per arah } \\
\text { hadap } \\
\text { dilakukan 2x } \\
\text { angkatan kaki } \\
\text { kanan dan }\end{array}$ & $\begin{array}{l}5-8 \\
3 \times 8 \\
1-4 \\
5-8 \\
1-8\end{array}$ \\
\hline
\end{tabular}

\begin{tabular}{|c|c|c|c|}
\hline & & $\begin{array}{l}\text { kiri. } \\
\text {-Mundur } \\
\text { kanan angkat } \\
\text { kaki kiri, } \\
\text { mundur kiri } \\
\text { angkat kaki } \\
\text { kanan 4x. } \\
\text {-Maju jalan } \\
\text { kecil-kecil, } \\
\text { tangan kiri } \\
\text { nyawuk kanan } \\
\text { sampur kanan } \\
\text { ditarik ke } \\
\text { pinggang. } \\
\text {-Gêjug-gêjug } \\
\text { kaki kanan, } \\
\text { egol sambil } \\
\text { tangan kanan } \\
\text { ukêl-ukêl. } \\
\text {-Mundur } \\
\text { kanan angkat } \\
\text { kaki kiri, } \\
\text { mundur kiri } \\
\text { angkat kaki } \\
\text { kanan 4x. }\end{array}$ & \\
\hline 29. & Gêjugan & $\begin{array}{l}\text {-Gêjug 3x kaki } \\
\text { kanan } \\
\text { kemudian } \\
\text { ngancap. } \\
\text {-Jalan biasa } \\
\text { kedepan } 4 \\
\text { hitungan. } \\
\text {-Mundur kaki } \\
\text { kiri, ukêl } \\
\text { tangan kanan, } \\
\text { kêbyok } \\
\text { kêbyak } \\
\text { sampur kiri, } \\
\text { képat sampur } \\
\text { kanan. } \\
\text {-Jalan biasa } \\
\text { lagi } 4 \\
\text { hitungan } \\
\text { kemudian } \\
\text { srisig. }\end{array}$ & $\begin{array}{l}1-4 \\
5-8 \\
1-4\end{array}$ \\
\hline
\end{tabular}




\begin{tabular}{|c|c|c|c|}
\hline 30. & Ikêt & $\begin{array}{l}\text { Mundur kaki } \\
\text { kiri, ukêl } \\
\text { tangan kanan, } \\
\text { kêbyok } \\
\text { kêbyak } \\
\text { sampur kiri, } \\
\text { képat sampur } \\
\text { kanan. }\end{array}$ & $5-8$ \\
\hline 31. & Sabêtan & $\begin{array}{l}\text { Junjungan kaki } \\
\text { kanan kêtêr, } \\
\text { kêbyok } \\
\text { sampur kiri, } \\
\text { képatsampur } \\
\text { kanan, gêjug } \\
\text { kanan. }\end{array}$ & $1-8+4$ \\
\hline 32. & Ikêt & $\begin{array}{l}\text { Mundur kaki } \\
\text { kiri, ukêl } \\
\text { tangan kanan, } \\
\text { kêbyok } \\
\text { kêbyak } \\
\text { sampur kiri, } \\
\text { képat sampur } \\
\text { kanan. }\end{array}$ & $5-8$ \\
\hline 33. & $\begin{array}{l}\text { Bumi langit } \\
\text { låmbå- } \\
\text { rangkêp }\end{array}$ & $\begin{array}{l}\text {-Tangan kanan } \\
\text { dan kiri } \\
\text { bergantian } \\
\text { ngrawit serong } \\
\text { ke kanan dan } \\
\text { kiri, låmbå 4x. } \\
\text {-Rangkêp } \\
\text { (kedua tangan } \\
\text { kebawah } \\
\text { keatas 5x). } \\
\text {-Képat sampur } \\
\text { kanan, gêdrug } \\
\text { låmbå. } \\
\end{array}$ & $7-8+4$ \\
\hline 34. & Ikêt & $\begin{array}{l}\text { Mundur kaki } \\
\text { kiri, ukêl } \\
\text { tangan kanan, } \\
\text { kêbyok } \\
\text { kêbyak } \\
\text { sampur kiri, } \\
\text { képat sampur } \\
\text { kanan. }\end{array}$ & $5-8$ \\
\hline
\end{tabular}

\begin{tabular}{|c|c|c|c|}
\hline 35. & Sabêtan & $\begin{array}{l}\text { Junjungan kaki } \\
\text { kanan kêtêr, } \\
\text { kêbyok } \\
\text { sampur kiri, } \\
\text { képat sampur } \\
\text { kanan, gêjug } \\
\text { kanan. }\end{array}$ & $1-8+4$ \\
\hline 36. & Ikêt & $\begin{array}{l}\text { Mundur kaki } \\
\text { kiri, ukêl } \\
\text { tangan kanan, } \\
\text { kêbyok } \\
\text { kêbyak } \\
\text { sampur kiri, } \\
\text { képatsampur } \\
\text { kanan. }\end{array}$ & $5-8$ \\
\hline 37. & $\begin{array}{l}\text { Bumi langit } \\
\text { rangkêp }\end{array}$ & $\begin{array}{l}\text { Kedua tangan } \\
\text { kebawah dan } \\
\text { atas } 4 x .\end{array}$ & $1-4$ \\
\hline 38. & Sêmbahan & $\begin{array}{l}\text {-Gêjug kanan } \\
\text { 4x, tangan kiri } \\
\text { nyawuksampu } \\
\text { r kanan ditarik } \\
\text { pinggang, } \\
\text { tangan kanan } \\
\text { lurus } \\
\text { pinggang, } \\
\text { tolehan ke } \\
\text { kiri. } \\
\text {-Melangkah } \\
\text { kiri kanan, } \\
\text { hadap depan. } \\
\text {-Sêmbah, kaki } \\
\text { sejajar }\end{array}$ & $5-6$ \\
\hline 39. & $\begin{array}{l}\text { Mundur } \\
\text { gawang }\end{array}$ & $\begin{array}{l}\text { Tindak mulih, } \\
\text { keluar } \\
\text { panggung. }\end{array}$ & \\
\hline
\end{tabular}




\section{Dalam repertoar Tari Remo Putri} gaya Tawi, susunan pola komposisi gerak terdiri dari bagian A yang berisi 15 ragam gerak. Selanjutnya diteruskan dengan bagian B yang berisi 20 ragam gerak. Pada bagian B ini sifat kênès nampak sekali pada gerakgeraknya. Berikutnya adalah bagian C (masuk dalam gending tropongan) yang terdiri dari 9 ragam gerak. Karena mengakhiri tarian maka sifat gerak cenderung meningkat rasa semangatnya untuk menuju relaksasi.

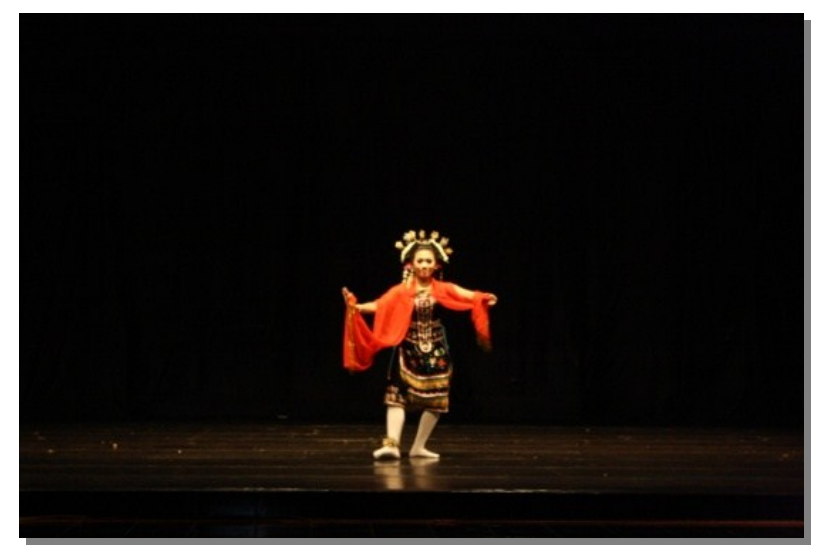

Foto : Gerak adeg

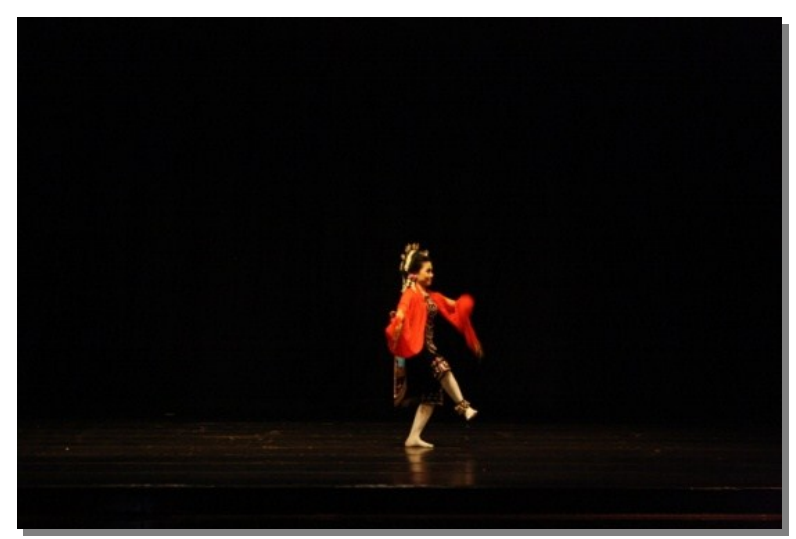

Foto : Gerak junjungan pada iket sabetan

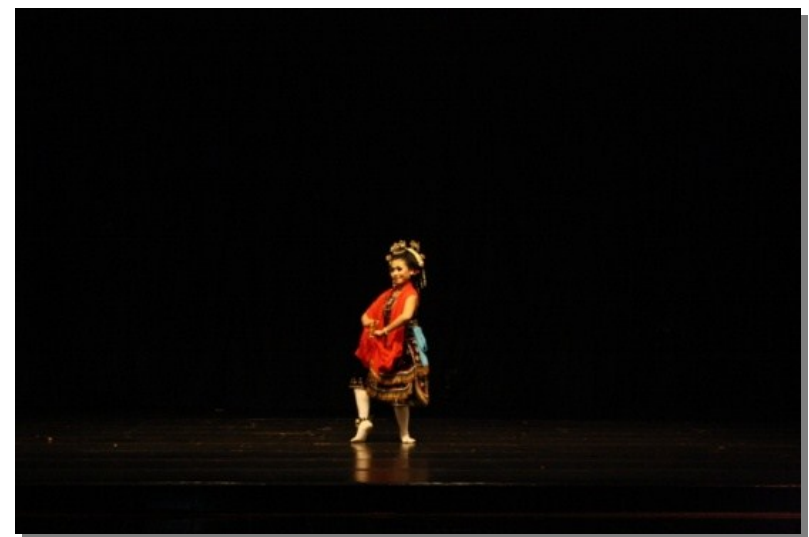

Foto : Gerak persiapan tindak kencak

\section{PENUTUP}

Dalam proses pelaksanaan rekonstruksi gerak harus dilandasi dengan wawasan konseptual. Kreativitas dalam proses tafsir menemukan warna baru dalam sajian tari, diperlukan untuk dapat mengasah kemampuan penulis sekaligus pelaku dalam membedah sajian yang lama dengan sajian yang baru, agar kebaruan dalam penyajian dapat diterima oleh perkembangan arus globalisasi yang begitu pesat denganmempertahankan esensi dan tetap berpedoman pada kaidah-kaidah atau pedoman yang berlaku.

\section{DAFTAR SUMBER ACUAN}

\section{A. Sumber Tercetak}

Humardani, 1979/1980, Kumpulan Kertas tentang Tari. Surakarta, ASKI Surakarta

Pramutomo, 2007, Etnokoreologi Nusantara

(Batasan Kajian, Sistematika, dan Aplikasi

Keilmuannya), Surakarta: ISI Press 
Sutopo, H.B, 2002, Metodologi Penelitian

(Dasar teori dan terapannya dalam penelitian), Surakarta : Sebelas Maret University Press

Wahyudiyanto, 2008, Pengetahuan Tari,

Solo, ISI Press

2009, Wajah Tari dalam

Perspektif. Surakarta: ISI Press

\section{B. Nara Sumber}

Tawi (75 tahun) pencipta Tari Remo Tawi Jombang, yang dahulu juga sebagai pengreman dalam kelompok Ludruk Kuda Bhirawa. 